\title{
Disparate consequences of heat stress exposure during meiotic maturation: embryo development after chemical activation vs fertilization of bovine oocytes
}

\author{
L A Rispoli, J L Lawrence, R R Payton, A M Saxton, G E Schrock, F N Schrick, B W Middlebrooks, \\ J R Dunlap ${ }^{1}$, J J Parrish² and J L Edwards \\ Department of Animal Science, Institute of Agriculture, UT AgResearch, The University of Tennessee, 102 McCord \\ Hall, 2640 Morgan Circle Drive, Knoxville, Tennessee 37996-4574, USA, ${ }^{1}$ Division of Biology, Microscopy and \\ Imaging Center, The University of Tennessee, Knoxville, Tennessee 37996-0830, USA and ${ }^{2}$ Department of Animal \\ Science, The University of Wisconsin, Madison, Wisconsin 53706, USA
}

Correspondence should be addressed to J L Edwards; Email: jedwards@utk.edu

\begin{abstract}
Consequences of heat stress exposure during the first $12 \mathrm{~h}$ of meiotic maturation differed depending on how and when bovine oocytes were activated. If heat-stressed oocytes underwent IVF at $\sim 24 \mathrm{~h}$, blastocyst development was less than for respective controls and similar to that obtained for nonheat-stressed oocytes undergoing IVF at $30 \mathrm{~h}$ (i.e. slightly aged). In contrast, if heat-stressed oocytes underwent chemical activation with ionomycin/6-dimethylaminopurine at $24 \mathrm{~h}$, blastocyst development was not only higher than respective controls, but also equivalent to development obtained after activation of nonheat-stressed oocytes at $30 \mathrm{~h}$. Developmental differences in chemically activated vs IVF-derived embryos were not related to fertilization failure or gross alterations in cytoskeletal components.

Rather, ionomycin-induced calcium release and MAP kinase activity were less in heat-stressed oocytes. While underlying mechanisms are multifactorial, ability to obtain equivalent or higher development after parthenogenetic activation demonstrates that oocytes experiencing heat stress during the first $12 \mathrm{~h}$ of meiotic maturation have the necessary components to develop to the blastocyst stage, but fail to do so after fertilization.
\end{abstract}

Reproduction (2011) 142 831-843

\section{Introduction}

Heat stress is an important economic problem in agricultural animals in large part because of heatinduced reductions in fertility. Reduced fertility is problematic when females experience hyperthermia near the time period of breeding (bovine, Stott \& Williams 1962; ovine, Dutt 1963; porcine, Tompkins et al. 1967). Extensive research in the bovine has demonstrated direct consequences of elevated temperature on the maturing oocyte. For instance, Putney et al. (1989) reported reductions in embryonic viability when rectal temperatures were elevated during estrus. Similar consequences were noted after direct application of physiologically relevant elevated temperatures to oocytes undergoing maturation in vitro (Edwards \& Hansen 1996, Edwards et al. 2005, Schrock et al. 2007).

Marked changes occurring in the nucleus and ooplasm may explain why maturing oocytes are susceptible to direct effects of elevated body temperatures. Although the magnitude of response in bovine oocytes depends on severity and duration (Edwards \&
Hansen 1996, Payton et al. 2004), consequences after direct application include heat-induced reductions in embryonic development by as much as $42-65 \%$ (Edwards \& Hansen 1996, Roth \& Hansen 2004a, Edwards et al. 2005, Schrock et al. 2007) and yet unidentified effects that carry over to alter competence of otherwise morphologically normal embryos (Edwards et al. 2009).

Although underlying mechanism(s) remain unclear, collective findings in two different species document effects of physiologically relevant heat stress exposures during meiotic maturation to hasten developmentally important processes. For instance, Baumgartner \& Chrisman (1981) reported a higher incidence of murine oocytes having a bicellular classification (i.e. oocytes contained two cells, with one presumed to be the first polar body) after in vivo heat stress exposure. This is consistent with results reported by Kim et al. (2002) suggesting that a short-term heat shock permissive of meiotic maturation in murine oocytes accelerated germinal vesicle breakdown. After direct application of heat stress, Edwards et al. (2005) demonstrated that more 
bovine oocytes progressed to metaphase I by $8 \mathrm{~h}$ of in vitro maturation (hIVM), metaphase II by 18 hIVM, and completed cortical granule translocation to the oolemma by 24 hIVM compared with those not exposed to heat stress. Also, heat stress exposure between 18 and $21 \mathrm{hIVM}$ increased the percentage of bovine oocytes exhibiting a type IV cortical granule distribution suggesting earlier exocytosis (Andreu-Vazquez et al. 2010).

Regardless of the specific process or component affected, Schrock et al. (2007) showed that earlier fertilization increased developmental competence of heat-stressed oocytes. Using multi-source regression, optimal development for heat-stressed oocytes depended on performing IVF at 19.5 hIVM compared with 26.7 hIVM for nonheat-stressed controls. Collectively, these findings provide compelling evidence for heat-stressed oocytes to mature faster than nonheatstressed counterparts. To this end, fertilization of heatstressed oocytes during the 'fertile window of time' ascribed for nonheat-stressed oocytes would effectively result in the fertilization of an 'aged' oocyte.

To further test the heat-induced 'aging hypothesis' initially postulated but not investigated by Baumgartner \& Chrisman (1981), experiments were conducted to examine the development of heat-stressed oocytes after chemical activation with ionomycin followed by 6-dimethylaminopurine exposure as per Susko-Parrish et al. (1994). Preference for use of this parthenogenetic model was based on previous efforts showing responsiveness of bovine oocytes to be age-dependent (i.e. aged oocytes activate more readily than younger oocytes; Susko-Parrish et al. 1994). Also, this approach has been demonstrated to support embryo and fetal development of somatic cell nuclear transfer clones (Davies et al. 2004, Lawrence et al. 2004).

In the first study, developmental competence of heatstressed oocytes was assessed after chemical activation at 19 vs 24 hIVM. In a second study, developmental competence of heat-stressed oocytes was assessed after chemical activation or IVF at 24 or 30 hIVM. Results from those two studies prompted a closer examination of fertilization rates, intracellular calcium release and activity related to maturation-promoting factor (MPF) and MAP kinase in control, heat-stressed, and aged oocytes. Since consequences of heat stress and aging may include perturbations in cytoskeletal components (Eichenlaub-Ritter et al. 1986, Tarin 1996, Ju \& Tseng 2004, Roth \& Hansen 2005), F-actin in maturing oocytes was also examined.

\section{Results \\ Development of heat-stressed oocytes after chemical activation at 19 or 24 hIVM}

Cumulus-oocyte complexes were matured at 38.5 (control) or $41.0^{\circ} \mathrm{C}$ (heat stress was applied during first 12 hIVM only) and chemically activated with ionomycin/6-dimethylaminopurine at 19 or 24 hIVM. Heat stress exposure did not alter the proportion of oocytes recovered or those that had visibly lysed after denudement of cumulus cells before chemical activation at 19 or 24 hIVM (Table 1). The proportion of heat-stressed oocytes that underwent cleavage and blastocyst development after chemical activation at 19 and 24 hIVM was similar to those matured at $38.5^{\circ} \mathrm{C}$ (Table 1). Blastocyst stage scores were slightly lower in embryos from heat-stressed oocytes activated at 19 and 24 hIVM (Table 1). Independent of heat stress exposure, proportion of oocytes that were visibly lysed was slightly higher when denudement occurred at 24 vs 19 hIVM (Table 1). Ability of oocytes to undergo cleavage and progress to the 8- to 16-cell and blastocyst stages was higher when chemical activation was performed at $24 \mathrm{vs}$ 19 hIVM (Table 1).

Table 1 Embryo development of control $^{\mathrm{a}}$ and heat-stressed ${ }^{\mathrm{b}}$ bovine oocytes after chemical activation at 19 or 24 hIVM.

\begin{tabular}{|c|c|c|c|c|c|c|c|c|c|c|}
\hline \multirow[b]{2}{*}{$\begin{array}{l}\text { Oocyte } \\
\text { treatment }\end{array}$} & \multirow[b]{2}{*}{$\begin{array}{c}\text { Activation } \\
\text { time (hIVM) }\end{array}$} & \multirow[b]{2}{*}{$\begin{array}{c}\text { No. of } \\
\text { oocytes }\end{array}$} & \multirow[b]{2}{*}{$\operatorname{Rcd}(\%)^{\mathrm{C}}$} & \multirow[b]{2}{*}{ Lysed $(\%)^{d}$} & \multicolumn{3}{|c|}{ Cleavage $(71.5-74.5 \mathrm{hpa})$} & \multicolumn{3}{|c|}{ Blastocyst (186-194.5 hpa) } \\
\hline & & & & & Cleaved (\%) & $\begin{array}{l}\text { Four-cell } \\
(\%)^{\mathrm{e}}\end{array}$ & $\begin{array}{l}\text { 8- to } 16 \text {-cell } \\
(\%)^{\mathrm{e}}\end{array}$ & $\begin{array}{c}\text { Percent of } \\
\text { oocytes }\end{array}$ & $\begin{array}{l}\text { Percent of } \\
\text { cleaved }\end{array}$ & Stage \\
\hline Control & 19 & 539 & 95.6 & 0.4 & 50.5 & 10.0 & 76.1 & 19.1 & 37.9 & 6.3 \\
\hline Heat stress & 19 & 522 & 95.4 & 0.8 & 42.3 & 12.1 & 73.3 & 21.3 & 50.2 & 6.1 \\
\hline Control & 24 & 516 & 97.1 & 1.8 & 77.7 & 5.2 & 85.5 & 45.0 & 57.9 & 6.3 \\
\hline \multirow[t]{5}{*}{ Heat stress } & 24 & 470 & 96.2 & 1.6 & 74.0 & 7.3 & 83.1 & 44.7 & 60.3 & 6.2 \\
\hline & & S.E.M. & 1.4 & 0.5 & 4.3 & 2.6 & 3.7 & 3.0 & 4.1 & 0.06 \\
\hline & Oocyte trea & ent $P$ value & 0.661 & 0.610 & 0.207 & 0.157 & 0.469 & 0.697 & 0.090 & 0.020 \\
\hline & Activation & me $P$ value & 0.425 & 0.019 & $<0.0001$ & 0.005 & 0.014 & $<0.0001$ & 0.002 & 0.038 \\
\hline & ent $\times$ activatio & ime $P$ value & 0.777 & 0.448 & 0.759 & 0.713 & 0.931 & 0.644 & 0.256 & 0.587 \\
\hline
\end{tabular}

hIVM, hours of in vitro maturation; hpa, hours post activation.

${ }^{a}$ Control, oocytes were matured at $38.5^{\circ} \mathrm{C}$. ${ }^{b}$ Heat stress, $41^{\circ} \mathrm{C}$ was applied during first $12 \mathrm{hIVM}$ only; thereafter oocytes were matured at $38.5^{\circ} \mathrm{C}$.

${ }^{c}$ Rcd, oocytes recovered after denuding as a proportion of total number of oocytes matured. ${ }^{\mathrm{d}}$ Lysed, oocytes without an intact plasma membrane after denuding as a proportion of recovered. ${ }^{e}$ Relative to proportion of embryos cleaved. Significant $P$ values are shown in bold. 


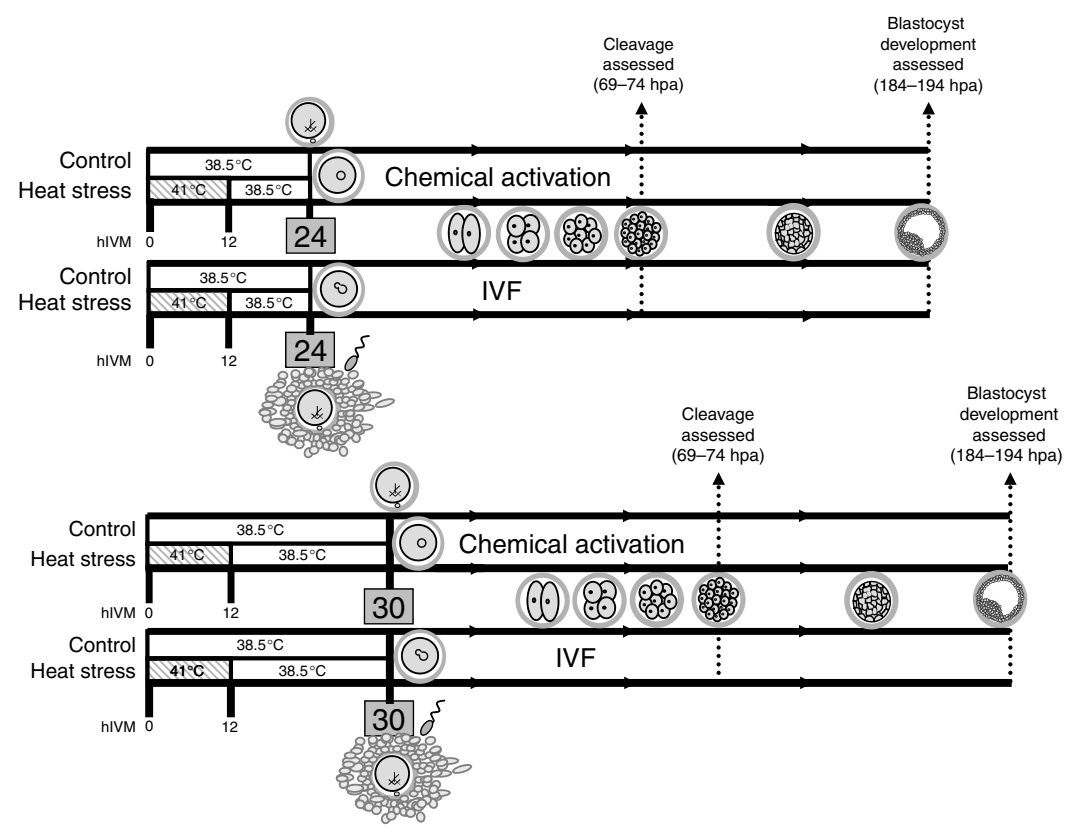

Figure 1 Schematic of experimental design for evaluating blastocyst development of bovine cumulus-oocyte complexes matured at $38.5^{\circ} \mathrm{C}$ (control) or $41.0^{\circ} \mathrm{C}$ (heat stress applied during first $12 \mathrm{~h}$ only) and undergoing chemical activation or IVF at 24 or $30 \mathrm{~h}$ of in vitro maturation (hIVM). This experiment was replicated on eight different occasions using a total of 164-282 cumulus-oocyte complexes per treatment group.

\section{Development of control, heat-stressed, and aged oocytes: different activation approaches and times}

Absence of heat stress effects to reduce blastocyst development in the first study prompted evaluation of development after cumulus-oocyte complexes, matured at $38.5^{\circ} \mathrm{C}$ or $41.0^{\circ} \mathrm{C}$ (heat stress applied during first 12 hIVM only), underwent chemical activation with ionomycin/6-dimethylaminopurine or IVF after 24 or 30 hIVM (experimental schematic provided in Fig. 1). Heat stress exposure did not alter the proportion of oocytes recovered or those that had visibly lysed after denudement of cumulus cells before chemical activation or after IVF at 24 or 30 hIVM (Table 2). When evaluating the proportion of oocytes that underwent cleavage and progressed to the 8- to 16-cell stages, no prominent heat stress effects were noted (Table 2). Rather, cleavage was most influenced by activation method and time (Table 2 ). For instance, performing IVF at 30 vs 24 hIVM decreased the proportion of 8- to 16-cell embryos and increased the proportion of two- and four-cell embryos, whereas

Table 2 Cleavage development of control $^{\mathrm{a}}$ and heat-stressed ${ }^{\mathrm{b}}$ bovine oocytes after undergoing chemical activation or IVF at 24 or 30 hIVM.

\begin{tabular}{|c|c|c|c|c|c|c|c|c|c|}
\hline \multirow[b]{2}{*}{$\begin{array}{l}\text { Oocyte } \\
\text { treatment }\end{array}$} & \multirow[b]{2}{*}{$\begin{array}{l}\text { Activation } \\
\text { method }\end{array}$} & \multirow[b]{2}{*}{$\begin{array}{l}\text { Activation } \\
\text { time (hIVM) }\end{array}$} & \multirow[b]{2}{*}{$\begin{array}{c}\text { No. of } \\
\text { oocytes/PZ }\end{array}$} & \multirow[b]{2}{*}{$\operatorname{Rcd}(\%)^{\mathrm{C}}$} & \multirow[b]{2}{*}{ Lysed $(\%)^{d}$} & \multicolumn{4}{|c|}{ Cleavage (69-74 hpa) } \\
\hline & & & & & & Cleaved (\%) & $\begin{array}{l}\text { Two-cell } \\
(\%)^{\mathrm{e}}\end{array}$ & $\begin{array}{c}\text { Four-cell } \\
(\%)^{\mathrm{e}}\end{array}$ & $\begin{array}{c}\text { 8- to 16-cell } \\
(\%)^{\mathrm{e}}\end{array}$ \\
\hline Control & $\mathrm{CA}$ & 24 & 262 & 96.1 & 0.6 & 77.1 & 6.9 & 3.5 & 89.6 \\
\hline Heat stress & CA & 24 & 281 & 96.1 & 0.2 & 82.6 & 5.6 & 6.0 & 88.4 \\
\hline Control & IVF & 24 & 211 & 92.4 & 1.2 & 76.8 & 8.6 & 3.1 & 88.3 \\
\hline Heat stress & IVF & 24 & 203 & 94.3 & 0.4 & 64.0 & 16.9 & 6.2 & 76.9 \\
\hline Control & CA & 30 & 225 & 96.0 & 0.8 & 88.0 & 6.6 & 2.0 & 91.4 \\
\hline Heat stress & CA & 30 & 209 & 96.0 & 1.4 & 87.6 & 6.0 & 6.0 & 88.0 \\
\hline Control & IVF & 30 & 153 & 92.5 & 1.6 & 60.8 & 20.4 & 14.0 & 65.6 \\
\hline \multirow[t]{8}{*}{ Heat stress } & IVF & 30 & 137 & 85.4 & 1.2 & 56.2 & 35.1 & 9.1 & 55.8 \\
\hline & & & S.E.M. & 2.3 & 1.3 & 4.1 & 3.6 & 2.5 & 4.9 \\
\hline & & \multicolumn{2}{|c|}{ Oocyte treatment $P$ value } & 0.707 & 0.336 & 0.457 & 0.242 & 0.148 & 0.088 \\
\hline & & \multicolumn{2}{|c|}{ Activation method $P$ value } & 0.009 & 0.320 & $<0.0001$ & $<0.0001$ & 0.075 & $<0.0001$ \\
\hline & Oocyte treat & \multicolumn{2}{|c|}{ t $\times$ activation method $P$ value } & 0.703 & 0.656 & 0.109 & 0.075 & 0.270 & 0.469 \\
\hline & & \multicolumn{2}{|c|}{ Activation time $P$ value } & 0.362 & 0.080 & 0.895 & 0.054 & 0.265 & 0.034 \\
\hline & Oocyte tr & \multicolumn{2}{|c|}{ nent $\times$ activation time $P$ value } & 0.356 & 0.227 & 0.944 & 0.914 & 0.622 & 0.875 \\
\hline & Activation & ethod $\times$ activat & n time $P$ value & 0.389 & 0.604 & 0.002 & 0.058 & 0.055 & 0.015 \\
\hline \multicolumn{4}{|c|}{ Oocyte treatment $\times$ activation method $\times$ activation time $P$ value } & 0.377 & 0.641 & 0.237 & 0.877 & 0.191 & 0.513 \\
\hline
\end{tabular}

hIVM, hours of in vitro maturation; hpa, hours post activation; CA, chemical activation; PZ, presumptive zygotes.

${ }^{a}$ Control, oocytes were matured at $38.5^{\circ} \mathrm{C}$. ${ }^{b}$ Heat stress, $41^{\circ} \mathrm{C}$ was applied during first $12 \mathrm{hIVM}$ only; thereafter oocytes were matured at $38.5{ }^{\circ} \mathrm{C}$. ${ }^{\mathrm{c}} \mathrm{Rcd}$, oocytes/PZ recovered after denuding as a proportion of total number of oocytes matured. ${ }^{\mathrm{d}}$ Lysed, oocytes/PZ without an intact plasma membrane after denuding as a proportion of recovered. ${ }^{e}$ Relative to proportion of embryos cleaved. Significant $P$ values are shown in bold. 


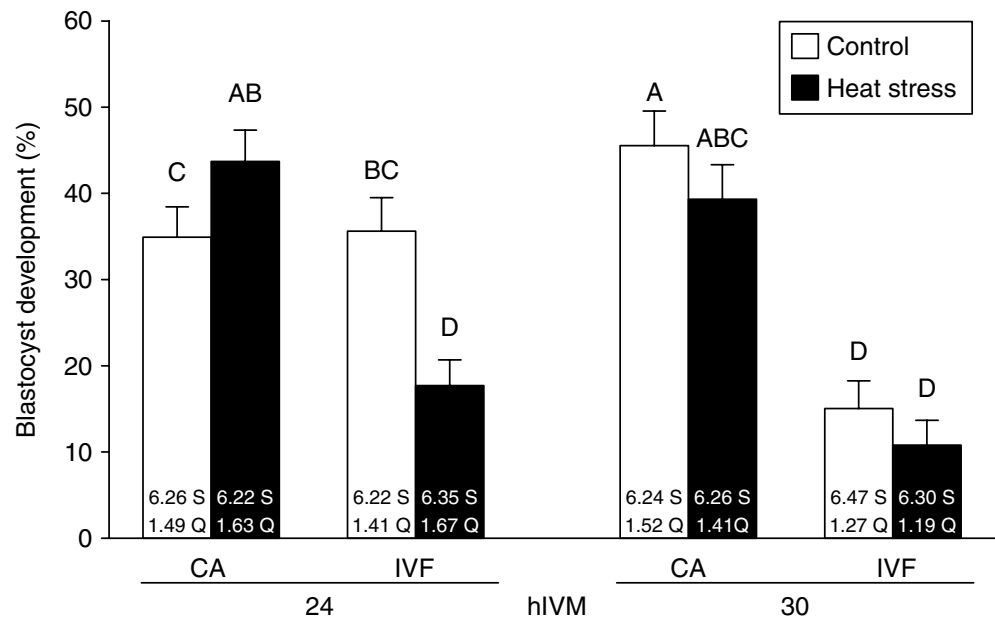

Figure 2 Least squares means for blastocyst development after bovine cumulus-oocyte complexes were matured at $38.5^{\circ} \mathrm{C}$ (control) or $41.0^{\circ} \mathrm{C}$ (heat stress applied during first $12 \mathrm{~h}$ only) and underwent chemical activation (CA) or IVF at 24 or $30 \mathrm{~h}$ of in vitro maturation (hIVM). There was an oocyte treatment $\times$ activation time $\times$ activation method interaction $(P=0.025$; S.E.M. $=3.5)$. ${ }^{A B C D}$ Bars with different letters differ. Numeric scores for blastocyst stage $(S)$ and quality $(\mathrm{Q})$ are indicated for each treatment combination within individual bars. chemical activation at 30 vs 24 hIVM did not alter the proportion of 2-, 4-, or 8- to 16-cell stage embryos.

The impact of heat stress exposure to affect blastocyst development differed depending on activation method and time (oocyte treatment $\times$ activation method $\times$ activation time interaction $P=0.025$; S.E.M. $=3.5$; Fig. 2 ). Specifically, when heat stress exposure occurred during the first $12 \mathrm{~h}$ of meiotic maturation and oocytes underwent IVF at 24 hIVM, blastocyst development was lower than for respective nonheat-stressed controls. However, when heat-stressed oocytes underwent chemical activation at 24 hIVM, blastocyst development was higher than for respective nonheat-stressed controls and equivalent to development of nonheat-stressed oocytes chemically activated at 30 hIVM (i.e. slightly aged oocytes). At 30 hIVM, blastocyst development of heatstressed oocytes after chemical activation was similar to respective nonheat-stressed controls. Blastocyst development of nonheat-stressed oocytes undergoing IVF at 30 hIVM was similar to that obtained for heatstressed oocytes undergoing IVF at 24 hIVM. Performing IVF at 30 hIVM did not result in further reductions in the development of heat-stressed oocytes. Stage and quality scores of resultant blastocysts were similar regardless of maturation temperature or activation method.

\section{Fertilization and pronuclear formation in control, heat-stressed, and aged oocytes}

Cumulus-oocyte complexes were matured at $38.5^{\circ} \mathrm{C}$ or $41.0^{\circ} \mathrm{C}$ (heat stress was applied during first $12 \mathrm{hIVM}$ only) for $24 \mathrm{~h}$ or $38.5^{\circ} \mathrm{C}$ for $30 \mathrm{~h}$ (aged) before undergoing IVF. The proportion of oocytes that were penetrated and underwent pronuclear formation thereafter was evaluated at $6,10,13$, and $16 \mathrm{~h}(3 \times 4$ factorial treatment arrangement). Subsets of control and heatstressed oocytes (five out of eight total replicates) were allowed to develop to the blastocyst stage to document the extent to which heat stress reduced development. Using experimental conditions whereby heat stress reduced blastocyst development by $\sim 37 \%$ without impacting cleavage rates (see Table 3), neither heat stress nor slight aging altered the ability of oocytes to undergo penetration or pronuclear formation (Table 4).

\section{Actin filaments in heat-stressed oocytes}

Cumulus-oocyte complexes were assessed at 38.5 (control), $41.0^{\circ} \mathrm{C}$ or $43.0^{\circ} \mathrm{C}$ (heat stress temperatures applied during first 12 hIVM only). Heat stress exposure did not alter the proportion of oocytes recovered or those that had visibly lysed after denudement of cumulus cells.

Table 3 Embryo development of control $^{\mathrm{a}}$ and heat-stressed ${ }^{\mathrm{b}}$ bovine oocytes after IVF at 24 hIVM.

\begin{tabular}{|c|c|c|c|c|c|c|c|c|}
\hline \multirow[b]{2}{*}{$\begin{array}{l}\text { Oocyte } \\
\text { treatment }\end{array}$} & \multirow[b]{2}{*}{$\begin{array}{c}\text { No. of } \\
\text { oocytes }\end{array}$} & \multirow[b]{2}{*}{$\operatorname{Rcd}(\%)^{\mathrm{C}}$} & \multirow[b]{2}{*}{ Lysed $(\%)^{d}$} & \multicolumn{2}{|c|}{ Cleavage $(67-73 \mathrm{hpi})$} & \multicolumn{3}{|c|}{ Blastocyst (188-191 hpi) } \\
\hline & & & & Cleaved $(\%)$ & $\begin{array}{c}\text { 8- to 16-cell } \\
(\%)^{\mathrm{e}}\end{array}$ & Percent of PZ & Stage & Quality \\
\hline Control & 250 & 93.2 & 4.7 & 75.3 & 82.5 & $35.3^{*}$ & 6.3 & 1.5 \\
\hline Heat stress & 250 & 93.2 & 4.3 & 66.6 & 80.2 & $22.2^{\dagger}$ & 6.3 & 1.9 \\
\hline \multirow{2}{*}{\multicolumn{2}{|c|}{$\begin{array}{l}\text { S.E.M. } \\
P \text { value }\end{array}$}} & 1.6 & 1.4 & 5.0 & 6.8 & 1.1 & 0.2 & 0.14 \\
\hline & & 1.0 & 0.832 & 0.133 & 0.645 & 0.008 & 0.794 & 0.107 \\
\hline
\end{tabular}

hIVM, hours of in vitro maturation; hpi, hours post IVF; PZ, presumptive zygotes.

${ }^{a}$ Control: oocytes were matured at $38.5^{\circ} \mathrm{C}$. ${ }^{b}$ Heat stress, $41^{\circ} \mathrm{C}$ was applied during first 12 hIVM only; thereafter oocytes were matured at $38.5^{\circ} \mathrm{C}$.

${ }^{\mathrm{c}} \mathrm{Rcd}$, oocytes/PZ recovered after denuding as a proportion of total number of oocytes matured. ${ }^{\mathrm{d}}$ Lysed, oocytes/PZ without an intact plasma

membrane after denuding as a proportion of recovered. ${ }^{e}$ Relative to proportion of embryos cleaved. ${ }^{*},{ }^{+}$Means within a column differ. Significant

$P$ values are shown in bold. 
Table 4 Fertilization and pronuclear formation in control $^{\mathrm{a}}$, heat-stressed ${ }^{\mathrm{b}}$, and aged ${ }^{\mathrm{c}}$ bovine oocytes.

\begin{tabular}{|c|c|c|c|c|c|c|}
\hline Oocyte treatment & Hours after IVF & No. evaluated & Fertilized $^{\mathrm{d}}(\%)$ & Monospermic $^{\mathrm{e}}(\%)$ & $\mathbf{P N F}^{f}(\%)$ & $2 \mathbf{P N}^{\mathrm{g}}(\%)$ \\
\hline Control & 6 & 173 & 29.8 & 96.2 & - & - \\
\hline Heat stress & 6 & 180 & 34.4 & 95.6 & - & - \\
\hline Aged & 6 & 105 & 34.4 & 87.5 & - & - \\
\hline Control & 10 & 165 & 67.4 & 77.1 & 26.8 & 66.7 \\
\hline Heat stress & 10 & 176 & 55.1 & 85.9 & 29.0 & 62.5 \\
\hline Aged & 10 & 108 & 57.1 & 79.2 & 52.8 & 68.0 \\
\hline Control & 13 & 172 & 68.7 & 82.1 & 67.8 & 90.9 \\
\hline Heat stress & 13 & 143 & 71.5 & 71.4 & 64.4 & 89.6 \\
\hline Aged & 13 & 103 & 61.0 & 62.2 & 67.2 & 92.0 \\
\hline Control & 16 & 172 & 75.0 & 67.9 & 86.7 & 92.1 \\
\hline Heat stress & 16 & 168 & 77.5 & 72.2 & 83.5 & 94.9 \\
\hline \multirow[t]{5}{*}{ Aged } & 16 & 92 & 72.6 & 72.5 & 79.1 & 88.9 \\
\hline & & S.E.M. & 7.2 & 5.5 & 7.9 & 6.8 \\
\hline & & treatment $P$ value & 0.723 & 0.094 & 0.740 & 0.979 \\
\hline & & $\mathrm{s}$ after IVF $P$ value & $<0.0001$ & $<0.0001$ & $<0.0001$ & 0.0003 \\
\hline & Oocyte treatment $x$ & $\mathrm{~s}$ after IVF $P$ value & 0.516 & 0.096 & 0.403 & 0.889 \\
\hline
\end{tabular}

hIVM, hours of in vitro maturation; PNF, pronuclear formation; PN, pronuclei.

${ }^{a}$ Control, oocytes were matured at $38.5^{\circ} \mathrm{C}$ for $24 \mathrm{~h}$. ${ }^{\mathrm{b}} \mathrm{Heat}$ stress, $41^{\circ} \mathrm{C}$ was applied during first $12 \mathrm{hIVM}$ only; thereafter oocytes were matured at $38.5^{\circ} \mathrm{C}$. ${ }^{\mathrm{c}}$ Aged, oocytes were matured at $38.5^{\circ} \mathrm{C}$ for $30 \mathrm{~h}$. ${ }^{\mathrm{d}}$ Fertilized, proportion of oocytes penetrated by at least one spermatozoon.

${ }^{\mathrm{e}}$ Monospermic, proportion of fertilized oocytes at different stages of meiosis (e.g. MII, All, TII, pronucleus) that were penetrated by one spermatozoon as indicated by the presence of a condensed or swollen sperm head, or as a pronucleus. PNF, proportion of monospermic oocytes having at least one pronuclear structure. ${ }^{2} 2 \mathrm{PN}$, proportion of PNF that had two pronuclei at time of evaluation. Significant $P$ values are shown in bold.

However, it was noted during staining procedure manipulations that more oocytes exposed to $43^{\circ} \mathrm{C}$ underwent lysis $\left(59.1 \%\right.$ vs 13.5 and $22.2 \%$ for $43.0^{\circ} \mathrm{C}$, $38.5^{\circ} \mathrm{C}$, and $41.0^{\circ} \mathrm{C}$, respectively; $P<0.01$; S.E.M. $=6.2$ ).

When matured at $38.5^{\circ} \mathrm{C}$ or $41.0^{\circ} \mathrm{C}$ for 12 or 24 hIVM, F-actin staining as assessed using fluorescent-labeled phalloidin was localized to the cortex in majority of oocytes examined (Fig. 3A-D and G-J). In a few oocytes, light but diffuse staining was noted in ooplasm (Fig. 3B). In some oocytes matured at $41^{\circ} \mathrm{C}$ for 12 hIVM (Fig. 3D), intense staining as spherical shapes was also noted. Although proportionately fewer, F-actin staining in majority of membrane-intact oocytes after $43.0^{\circ} \mathrm{C}$ exposure was similar to those undergoing maturation at $38.5^{\circ} \mathrm{C}$ or $41.0^{\circ} \mathrm{C}$. However, in some of the oocytes examined at $12 \mathrm{hIVM}$ at $43.0^{\circ} \mathrm{C}$, microfilament breaks were noted (Fig. 3E and F). These were not detected when oocytes were examined at 24 hIVM; rather, dense staining was noted in ooplasm and was also localized to cortex (Fig. 3K and L). No fluorescence was observed in oocytes when the Alexa Fluor 594-conjugated phalloidin was omitted from the staining procedure.

\section{Ionomycin-induced calcium release in control, heat- stressed, and aged oocytes}

Since loss of heat stress effects to reduce blastocyst development was coincident with calcium ionophore exposure, basal levels of free cytosolic calcium and its release after ionomycin exposure in control, heatstressed, and aged Fura-2-loaded oocytes were examined (representative image and variables of interest depicted in Fig. 4). If the external medium contained calcium, basal (i.e. resting) levels of intracellular calcium did not differ between control (24 hIVM at $\left.38.5^{\circ} \mathrm{C}\right)$, heat-stressed $\left(12\right.$ of the 24 hIVM at $41.0^{\circ} \mathrm{C}$ ), and aged (30-32 hIVM at $38.5^{\circ} \mathrm{C}$ ) oocytes (Table 5). lonomycin exposure stimulated immediate calcium release; time of rise (i.e. time from initiation of release until maximum peak), amplitude of release (i.e. difference between basal and maximum peak), area under the curve and post-release plateau of intracellular calcium concentrations were similar in control, heatstressed, and aged oocytes (Table 5). Interestingly, the time of decline in intracellular calcium levels (i.e. time from maximum peak until plateau level was reached) was longer in heat-stressed oocytes compared with control and aged oocytes. Consequently, the duration of release (time from initiation to termination of intracellular calcium release in response to ionomycin) was longer in heat-stressed oocytes compared with controls and aged oocytes (Table 5).

Evaluating ionomycin-induced intracellular calcium release using a calcium-deficient medium allowed for assessing calcium release from intracellular stores. When compared with nonheat-stressed controls, response of heat-stressed oocytes to ionomycin was similar (i.e. comparable times in the rise and decline of intracellular calcium concentrations and duration of response). Differences included lower intracellular basal levels of calcium, amplitude of its release, total area under the curve, and post-release plateau indicating heat-induced perturbations in calcium stores and/or components important for release (Table 5). Distinguishing features of aged oocytes included higher basal levels of intracellular calcium and quicker response to ionomycin than observed in control and heat-stressed oocytes (Table 5). While the amplitude of response was 
12 hIVM
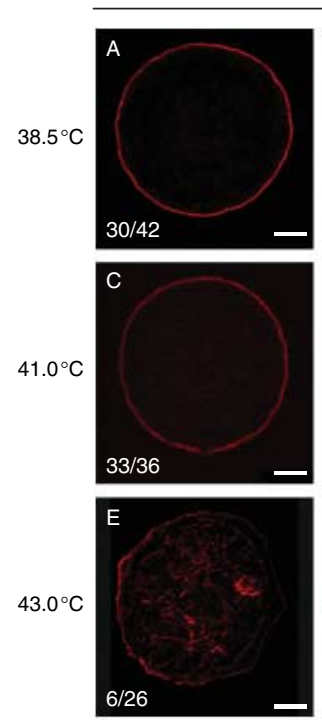
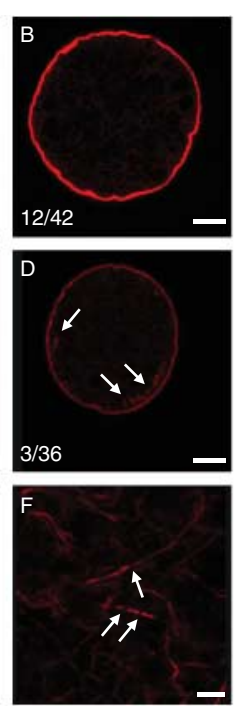

24 hIVM
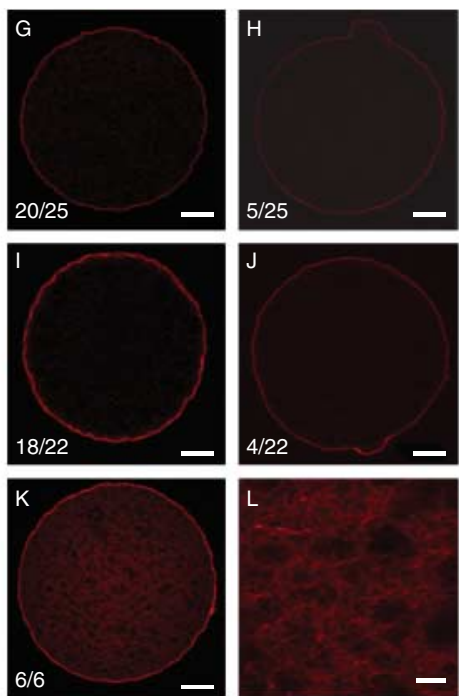

Figure 3 Representative confocal images of F-actin localization in bovine oocytes matured at $38.5^{\circ} \mathrm{C}$ (control), $41.0{ }^{\circ} \mathrm{C}$ or $43.0{ }^{\circ} \mathrm{C}$ (heat stress temperatures applied during first $12 \mathrm{~h}$ only). Regardless of temperature, most oocytes matured for $12 \mathrm{~h}$ of in vitro maturation (hIVM), had the majority of staining at the oolemma, forming a cortical ring $(\mathrm{A}-\mathrm{C}$, bar $=20 \mu \mathrm{m})$. Some oocytes matured at $41.0^{\circ} \mathrm{C}$ for the first 12 hIVM had round areas of intense staining underlying the oolemma $(\mathrm{D}$, bar $=20 \mu \mathrm{m})$. More extreme temperature of $43.0^{\circ} \mathrm{C}$ during the first $12 \mathrm{hIVM}$ induced some oocytes to display more prominent staining throughout the ooplasm $(\mathrm{E}$, bar $=20 \mu \mathrm{m})$ with distinct breaks in some microfilaments visualized $(\mathrm{F}$, bar $=4 \mu \mathrm{m}$, breakage indicated by arrows). At 24 hIVM, most oocytes had majority of staining at the cortex with diffuse staining throughout the ooplasm (G and I, bar $=20 \mu \mathrm{m})$ and prominent staining at the point of polar body extrusion ( $\mathrm{H}$ and J, bar $=20 \mu \mathrm{m})$. At $24 \mathrm{hIVM}$, oocytes exposed to $43.0{ }^{\circ} \mathrm{C}$ during the first 12 hIVM displayed a cortical ring of F-actin but also had a distinct network of F-actin throughout the ooplasm $(\mathrm{K}$, bar $=20 \mu \mathrm{m} ; \mathrm{L}$, bar $=4 \mu \mathrm{m})$. Each image was taken near the equatorial region of the oocyte. Panels ( $F$ and $L$ ) were generated using optical zoom on oocyte in preceding panel. The number of oocytes displaying each phenotype is indicated in the lower left corner of each panel.

similar to controls, duration of response was less and more comparable to that observed in heat-stressed oocytes. Post-release plateau values were highest in aged oocytes.

\section{MPF and MAP kinase activities in control, heat-stressed, and aged oocytes}

MPF activity was similar in control (24 hIVM at $\left.38.5^{\circ} \mathrm{C}\right)$, heat-stressed $\left(41.0^{\circ} \mathrm{C}\right.$ during first $12 \mathrm{hIVM}$ only, thereafter $\left.38.5^{\circ} \mathrm{C}\right)$, and aged $\left(32 \mathrm{hIVM}\right.$ at $\left.38.5^{\circ} \mathrm{C}\right)$ oocytes $(P=0.173$; Fig. 5A). In contrast, MAP kinase activity differed depending on treatment $(P=0.083)$. When compared with nonheat-stressed controls, heat stress exposure reduced MAP kinase activity $(P=0.047)$ to levels similar to those observed in aged oocytes $(P=0.886$; Fig. 5B).

\section{Discussion}

A parthenogenetic approach was utilized to further test the heat-induced 'aging' hypothesis, as age dependence of activation protocols sufficient to support pronuclear formation, cleavage, and blastocyst development has been well documented (i.e. older MII oocytes activate more readily than younger MII oocytes; Susko-Parrish et al. 1994, Suzuki et al. 1999, Tian et al. 2002). Results clearly showed that consequences of heat stress exposure during the first $12 \mathrm{~h}$ of meiotic maturation differed depending on how and when bovine oocytes were activated. For instance, if heat-stressed oocytes underwent IVF at $\sim 24$ hIVM, blastocyst development was less than respective control which is in agreement with numerous other studies (Edwards \& Hansen 1996, Lawrence et al. 2004, Roth \& Hansen 2004a, 2004b, Edwards et al. 2005, de Castro e Paula \& Hansen 2007, Schrock et al. 2007, Sugiyama et al. 2007, Soto \& Smith 2008, Zhandi et al. 2009). Furthermore, blastocyst development obtained after heat-stressed oocytes underwent IVF at 24 hIVM was similar to that obtained for nonheat-stressed oocytes undergoing IVF at 30 hIVM (i.e. slightly aged). In contrast, when heat-stressed oocytes underwent chemical activation at 24 hIVM, blastocyst development was not only higher than respective controls but also equivalent to development obtained after activation at 30 hIVM of slightly aged nonheat-stressed oocytes. Collectively, these findings along with previous results (Kim et al. 2002, Edwards et al. 2005, Schrock et al. 2007) provide compelling evidence for a major effect of heat stress exposure during the first part of meiotic maturation to hasten developmentally important processes.

Thus, fertilization of heat-stressed oocytes during the 'fertile window of time' ascribed for nonheat-stressed 


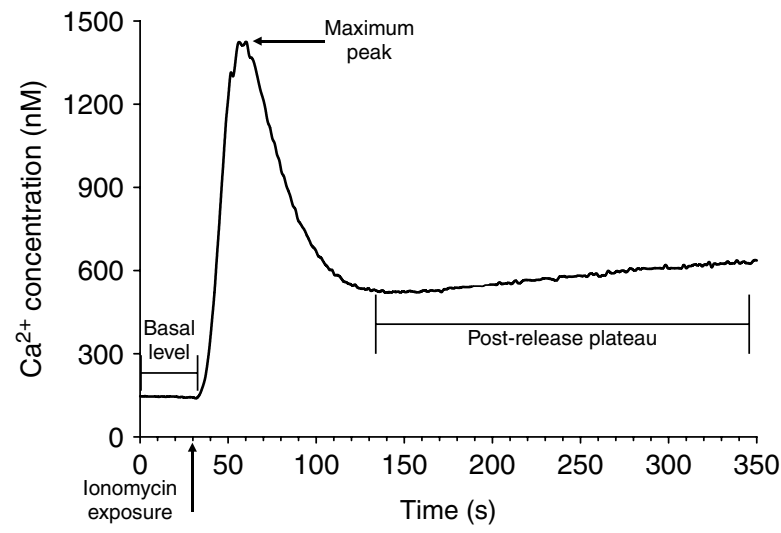

Figure 4 Representative image depicting calcium concentration (nM) in a bovine oocyte before and after ionomycin exposure. Analysis variables included basal levels (average intracellular levels before ionomycin addition), time of rise (time from addition of ionomycin until maximum peak), amplitude of release (difference between basal and maximum peak), area under the curve, time of decline (time from maximum peak until plateau level was reached), duration of release (time from initiation to termination of intracellular calcium release), and post-release plateau (average intracellular levels post termination of release).

oocytes likely results in the fertilization of an 'aged' oocyte. Notably, numerous similarities exist between heat-stressed oocytes and those that have been aged after reaching MII. Ward et al. (2002) and Agung et al. (2006) reported a $35-50 \%$ reduction in blastocyst development after oocytes were aged 8-10 h before IVF. Typically heat-stressed oocytes experience a $42-65 \%$ reduction in blastocyst development when IVF is performed at $\sim 24$ hIVM (Edwards \& Hansen 1996, Roth \& Hansen 2004a, Edwards et al. 2005, Schrock et al. 2007). Other pertinent similarities include reduced de novo synthesis of intracellular proteins and MAP kinase activity
(Edwards \& Hansen 1996, 1997, Xu et al. 1997, Ma et al. 2005, Lee \& Campbell 2006, Tatone et al. 2006, this study). Similar to aged oocytes, MAP kinase activity was lower in heat-stressed oocytes examined at 24 hIVM. Xu et al. (1997) associated partial decreases in MPF and MAP kinase activities to increased sensitivity of aged oocytes to calcium increasing agents, possibly providing some explanation for improved development of heat-stressed oocytes after chemical activation.

Disparate consequences of heat stress exposure during the first half of meiotic maturation to impact blastocyst development after activation with a chemical or a spermatozoon were not related to fertilization failure or obvious alterations in cytoskeleton. Examination of $>1700$ oocytes showed similar fertilization rates and pronuclear formation in control, heat-stressed, and aged oocytes, despite heat stress effects to reduce blastocyst development by $\sim 37 \%$. Additional efforts showed that the predominance of F-actin in the cortical region underlying the oolemma was similar to that reported by others in bovine (Li et al. 2005), porcine (Wang et al. 2000), and rat (Eliyahu et al. 2005, Meng et al. 2006) oocytes; $41.0^{\circ} \mathrm{C}$ exposure had minimal impact. Other studies reporting minimal to no heat stress effects on cleavage rates support fertilization and cytoskeletal data described herein (in vivo, Putney et al. 1989, Matsuzuka et al. 2004 and in vitro, Edwards \& Hansen 1996, Lawrence et al. 2004, Edwards et al. 2005, de Castro e Paula \& Hansen 2007, Schrock et al. 2007, Sugiyama et al. 2007, Edwards et al. 2009, Zhandi et al. 2009).

Notably, results document that oocytes experiencing heat stress during the first $12 \mathrm{~h}$ of meiotic maturation, like aged-MIl oocytes (Susko-Parrish et al. 1994), are capable of developing to the blastocyst stage (i.e. they have the necessary components) but fail to do so after fertilization. While the underlying mechanism(s) remain

Table 5 Characteristics of intracellular calcium levels before and after $5 \mu \mathrm{M}$ ionomycin exposure of control ${ }^{\mathrm{a}}$, heat-stressed ${ }^{\mathrm{b}}$, and aged ${ }^{\mathrm{c}}$ bovine oocytes.

\begin{tabular}{|c|c|c|c|c|c|c|c|c|}
\hline $\begin{array}{l}\text { Oocyte } \\
\text { treatment }\end{array}$ & $\begin{array}{c}\begin{array}{c}\text { No. of } \\
\text { evaluated }\end{array}\end{array}$ & $\begin{array}{c}\text { Basal levels } \\
\left(\mathrm{Ca}^{2+} \mathrm{nM}\right)\end{array}$ & $\begin{array}{l}\text { Time of } \\
\text { rise }^{d}(s)\end{array}$ & $\begin{array}{l}\text { Amplitude } \\
\text { of release } \\
\left(\mathrm{Ca}^{2+} \mathrm{nM}\right)\end{array}$ & $\begin{array}{c}\text { Time of } \\
\text { decline }^{f}(s)\end{array}$ & $\begin{array}{c}\text { Release } \\
\text { duration }^{\mathrm{g}}(\mathrm{s})\end{array}$ & $\begin{array}{l}\text { Area under } \\
\text { the curve }\end{array}$ & $\begin{array}{c}\text { Post-release } \\
\text { plateau } \\
\left(\mathrm{Ca}^{2+} \mathrm{nM}\right)\end{array}$ \\
\hline \multicolumn{9}{|c|}{ Calcium-containing medium } \\
\hline Control & 49 & 121.3 & 16.6 & 1198.3 & $52.6^{+}$ & $69.2^{+}$ & 52357 & 556.3 \\
\hline Heat stress & 44 & 116.8 & 15.4 & 1039.1 & $61.3^{*}$ & $79.6^{*}$ & 49629 & 448.7 \\
\hline Aged & 100 & 134.7 & 15.8 & 1153.2 & $53.8^{\dagger}$ & $69.5^{\dagger}$ & 47951 & 504.8 \\
\hline & & 6.7 & 0.6 & 113.2 & 2.8 & 3.0 & 4833 & 41.5 \\
\hline & & 0.112 & 0.373 & 0.613 & 0.009 & 0.048 & 0.709 & 0.141 \\
\hline \multicolumn{9}{|c|}{ Calcium-free medium } \\
\hline Control & 59 & $90.0^{\dagger}$ & $18.1^{*}$ & $685.7^{*}$ & 59.1 & $77.3^{*}$ & $28963^{*}$ & $213.1^{\dagger}$ \\
\hline Heat stress & 33 & $55.2^{\ddagger}$ & $18.2^{*}$ & $505.9^{+}$ & 55.5 & $73.8^{*,+}$ & $20894^{+}$ & $148.3^{\mp}$ \\
\hline Aged & 65 & $146.2^{*}$ & $14.7^{\dagger}$ & 787.9* & 55.4 & $70.1^{+}$ & $29935^{*}$ & $280.6^{*}$ \\
\hline \multirow{2}{*}{\multicolumn{2}{|c|}{$\begin{array}{l}\text { S.E.M. } \\
P \text { value }\end{array}$}} & 18.9 & 1.3 & 114.3 & 3.5 & 4.6 & 5785 & 37.3 \\
\hline & & $<0.0001$ & 0.0001 & 0.0004 & 0.250 & 0.042 & $<0.0001$ & $<0.0001$ \\
\hline
\end{tabular}

hIVM, hours of in vitro maturation.

${ }^{a}$ Control, oocytes were matured at $38.5^{\circ} \mathrm{C}$ for $24 \mathrm{~h}$. ${ }^{\mathrm{b}} \mathrm{Heat}$ stress, $41^{\circ} \mathrm{C}$ was applied during first 12 hIVM only; thereafter oocytes were matured at $38.5^{\circ} \mathrm{C}$. ${ }^{\mathrm{C}}$ Aged, oocytes were matured at $38.5^{\circ} \mathrm{C}$ for $30-32 \mathrm{~h} .{ }^{\mathrm{d}}$ Time in seconds from initiation of release until maximum peak reached. ${ }^{\mathrm{e}}$ Difference between initial basal and maximum peak intracellular calcium $\left(\left[\mathrm{Ca}^{2+}\right]_{\mathrm{i}}\right)$ levels. ${ }^{\mathrm{f}}$ Time in seconds from maximal peak until termination of release. gTime from initiation to termination of $\left[\mathrm{Ca}^{2+}\right]_{i}$ elevation. ${ }^{*},+{ }^{\ddagger}$ Means within a column and medium differ. Significant $P$ values are shown in bold. 


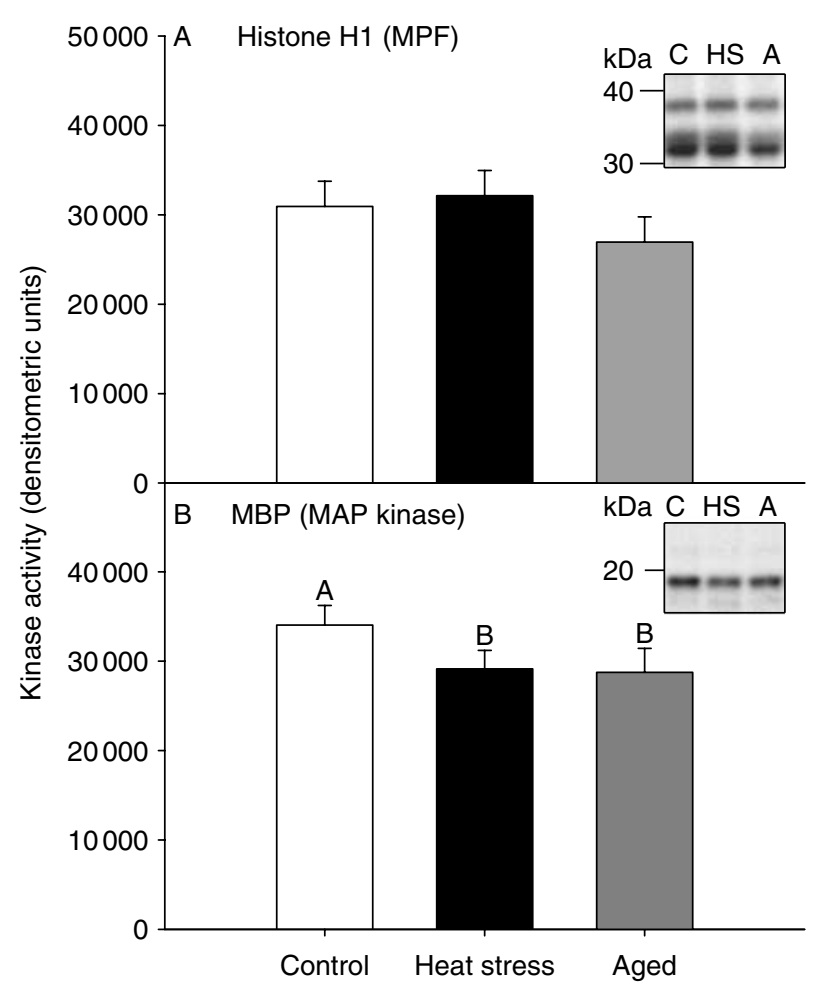

Figure 5 Relative kinase activity (densitometric units) for maturationpromoting factor (MPF) using histone $\mathrm{H} 1$ (panel A) and MAP kinase (MAP kinase; panel $\mathrm{B}$ ) using myelin basic protein (MBP) in bovine oocytes after maturation at $38.5^{\circ} \mathrm{C}$ (control (C)) or $41^{\circ} \mathrm{C}$ (heat stress, HS applied during first 12 hIVM only) for $24 \mathrm{~h}$ or at $38.5^{\circ} \mathrm{C}$ for $32 \mathrm{~h}$ (aged (A)). Insets within each panel depict a representative autoradiograph from phosphorylation of histone $\mathrm{H} 1$ and myelin basic protein respectively. ${ }^{\mathrm{AB}}$ Bars with different letters differ $(P<0.05)$.

unclear, ability to obtain equivalent or higher blastocyst development after exposure to chemicals targeting cytoplasmic components support the view for much of the negative heat stress effects to be occurring at the level of the ooplasm rather than nuclear components. Wang et al. (2009) came to a similar conclusion after performing chromosome spindle exchanges between murine oocytes matured in vivo and in vitro at different temperatures.

Loss of heat stress effects to reduce blastocyst development after parthenogenetic activation was functionally related to the induction of single calcium transient using ionomycin followed by inhibition of serine-threonine kinases with 6-dimethylaminopurine after cumulus denudement. Ionomycin exposure induces a single large calcium transient originating from internal stores and the external medium through effects on store-regulated $\mathrm{Ca}^{2+}$ channels (Morgan \& Jacob 1994, Dedkova et al. 2000). Additional effort showed that when calcium was present in the external medium, ionomycin-induced calcium release in heatstressed oocytes was comparable to that observed in nonheat-stressed and aged oocytes, with one notable exception. Decline in calcium levels was slower in heatstressed oocytes, suggesting possible heat-induced perturbations in components important for reducing cytosolic calcium levels (reviewed by Berridge et al. (2003)). Use of specific $\mathrm{Ca}^{2+}$-ATPase inhibitors targeting ATP-dependent $\mathrm{Ca}^{2+}$ pumps would allow for differentiating between possible effects occurring at the level of the endoplasmic reticulum or plasma membrane (Igarashi et al. 1997).

When the external medium was calcium deficient, several distinguishing features were noted in heatstressed oocytes. Basal levels were lower than nonheatstressed oocytes that represent the steady state achieved by balancing calcium leakage in and constant removal out of the cytosol (reviewed by Berridge et al. (2003)). Obtaining lower amplitude of response, area under the curve and post-release plateau after ionomycin exposure suggest possible heat-induced reductions of internal calcium stores or perturbations in components important for ionomycin-induced transients that may involve $\mathrm{IP}_{3}$-sensitive mechanisms (Xenopus laevis oocytes; Yoshida \& Plant 1992). Use of $\mathrm{IP}_{3}$-receptor agonists and antagonists would be helpful for discerning underlying mechanism(s). Depending on the extent to which alterations occur, developmentally important calcium oscillations induced by the fertilizing spermatozoon may be perturbed in heat-stressed oocytes. This seems plausible since developmental consequences of reduced amplitude or frequency of calcium oscillations in rabbit oocytes often parallel those observed after heat stress exposure (i.e. reduced compaction rates and blastocyst development (Ozil 1990, Edwards et al. 2009) and increased incidence of post-implantation/ attachment losses (Ozil \& Huneau 2001, Ozil et al. 2006, Rutigliano et al. 2008) without consequences on cleavage rates (Ozil \& Huneau 2001, Schrock et al. 2007, Edwards et al. 2009).

Although oocytes undergo numerous changes such as reorganization of the endoplasmic reticulum (Kruip et al. 1983) and increased number of $\mathrm{IP}_{3}$ receptors (He et al. 1997, Wang et al. 2005) for optimizing intracellular calcium responsiveness (reviewed by Ajduk et al. (2008)) during the first $12 \mathrm{~h}$ of maturation, heat-related consequences described herein may not be stage or species specific. For instance, Tseng et al. (2009) showed that a $2 \mathrm{~h}$ heat stress exposure after porcine oocytes had reached maturity (i.e. MII stage) reduced thimerosalinduced calcium release.

Bovine oocytes that had been slightly aged had higher basal levels of intracellular calcium that is consistent with preliminary work by Susko-Parrish et al. (1994) and consequences noted in murine oocytes (Takahashi et al. 2000). After ionomycin exposure, amplitude of calcium release was highest in aged oocytes. While consistent with consequences reported after aging MII murine oocytes (Vincent et al. 1992), these findings were inconsistent with results obtained for heat-stressed 
oocytes. This suggests heat-induced perturbations in specific ooplasmic component(s) important for calcium homeostasis or mobilization rather than merely a consequence of hastened maturation which may explain why performing earlier IVF is not entirely effective for eliminating negative heat stress effects on blastocyst development (Schrock et al. 2007). Since the calcium transient in heat-stressed oocytes was largely similar to that observed in nonheat-stressed oocytes, when calcium was present in the external medium, ionomycin exposure may have circumvented some of the potential problems related to perturbations in cytoplasmic component(s) important for calcium homeostasis or mobilization.

It is also possible for loss of heat stress effects to reduce blastocyst development after parthenogenetic activation to be functionally related to the absence of a sperm. In some instances glutathione content is lower in heat-stressed oocytes (Wang et al. 2009, Nabenishi et al. 2011). In our laboratory, heat-stressed oocytes may contain $\sim 12 \%$ less glutathione than nonheat-stressed counterparts (J L Edwards \& R R Payton 2011, unpublished observations). Important for reduction of disulfide bonds in the sperm nucleus, glutathione decreases after fertilization but remains unchanged after electricalinduced parthenogenetic activation (Funahashi et al. 1995). In the absence of a spermatozoon, activated oocytes would have an increased abundance of glutathione available to neutralize heat-induced increases in reactive oxygen species (Nabenishi et al. 2011).

Using a different stage of oocyte, others have noted a loss of heat stress effects after parthenogenetic activation. Tseng et al. (2009) performed chromosome spindle exchanges to isolate confounding effects of heat stress on the nucleus and ooplasm by applying $41.5^{\circ} \mathrm{C}$ for $2 \mathrm{~h}$ to porcine oocytes at MII stage and noted higher blastocyst development after parthenogenetic activation. Admittedly, results were not expected as in two different studies heat stress exposure reduced rather than increased blastocyst development (Tseng et al. 2006, Tseng \& Ju 2009). Because spindle exchanges took $\sim 1-2 \mathrm{~h}$, the importance of recovery time after heat stress exposure was speculated to be beneficial. Similarly, improved development herein was coincident with a $12 \mathrm{~h}$ recovery period after a heat stress exposure applied during the first $12 \mathrm{~h}$ of meiotic maturation. Disparate results of Tseng and coworkers were coincident with use of 1000-fold lower dose of 6-dimethylaminopurine, which may not be maximally effective to activate oocytes (Susko-Parrish et al. 1994). This may explain why Wang et al. (2009) did not observe a 'beneficial' effect of heat stress to improve blastocyst development when activating reconstructed murine oocytes with just $\mathrm{SrCl}_{2}$. Studies documenting negative impacts on blastocyst development after parthenogenetic activation (Tseng et al. 2006, Tseng \& Ju 2009, Wang et al. 2009) include cumulus denudement before activation procedure, effectively eliminating possible influences on loss of heat stress effects observed in this or other studies.

Current studies are focused on identifying components of the maturing oocyte affected by heat stress and consequences thereof, as it is this oocyte that will contribute $>99 \%$ of its cytoplasm and half of its genetic material to the resultant embryo after fertilization. Assessing the direct impact in vitro is a necessary first step toward identifying specific components in the in vivo matured oocyte altered by heat stress while resident within the Graafian follicle. Doing so is of utmost importance toward finding a solution to the problem of heat stress to alter oocyte competence and minimizing animal numbers necessary to conduct more focused in vivo studies.

\section{Materials and Methods}

\section{Materials}

Majority of reagents and chemicals were purchased from Sigma Chemical Co. Medium-199, gentamicin, penicillinstreptomycin, Fura-2/acetoxymethylester (Fura-2/AM), Fura-2 pentapotassium salt (Fura-2 salt), pluronic acid F-127, Alexa Fluor 594 phalloidin, and ProLong Gold antifade solution were purchased from Invitrogen. Fetal bovine serum (FBS) was obtained from BioWhittaker (Walkersville, MD, USA), whereas FSH (Folltropin-V) was obtained from Vetrepharm Canada, Inc. (London, ON, Canada). Ionomycin was purchased from Calbiochem (La Jolla, CA, USA) and Invitrogen. Oocyte collection medium was prepared in the laboratory containing M-199 with Hank's salts (Mediatech, Manassas, VA, USA), $1-2 \%$ (v/v) FBS, $2 \mathrm{mM}$ L-glutamine, $50 \mathrm{U} / \mathrm{ml}$ penicillin, and $50 \mu \mathrm{g} / \mathrm{ml}$ streptomycin. Oocyte maturation medium contained M-199 with Earle's salts (Invitrogen), 10\% (v/v) FBS, $50 \mu \mathrm{g} / \mathrm{ml}$ gentamicin, $5 \mu \mathrm{g} / \mathrm{ml}$ Folltropin- $\mathrm{V}, 0.2 \mathrm{mM}$ sodium pyruvate, and $2 \mathrm{mM}$ L-glutamine. Potassium simplex optimized medium was prepared in the laboratory according to Biggers et al. (2000) but modified to include $1 \mathrm{mM}$ glutamine, $10 \mathrm{mM}$ glycine, $1 \times$ non-essential amino acids, $50 \mathrm{U} / \mathrm{ml}$ penicillin, and $50 \mu \mathrm{g} / \mathrm{ml}$ streptomycin (mKSOM). Additional media including IVF Tyrode's albumin lactate pyruvate (IVF-TALP), Sperm-TALP, and HEPES-TALP were prepared as per Parrish et al. (1988). Frozen semen was donated by Harrogate Genetics International, Inc. (Harrogate, TN, USA). Bovine ovaries were purchased from a commercial abattoir (Brown Packing Company, Gaffney, SC, USA).

\section{General methods for in vitro production of embryos}

IVM, IVF and embryo culture were performed as described previously (Lawrence et al. 2004, Edwards et al. 2005, Schrock et al. 2007). Frozen-thawed Percoll-prepared semen from various bulls (500 000-600 000 motile sperm/ml; dairy and beef breeds; two of which were pooled on a given day) were used for each experimental replicate requiring IVF. Presumptive zygotes were cultured in $500 \mu \mathrm{l}$ of $\mathrm{mKSOM}$ at $38.5{ }^{\circ} \mathrm{C}$ in $5.5 \% \mathrm{CO}_{2}, 7.0 \% \mathrm{O}_{2}$, and $87.5 \% \mathrm{~N}_{2}$. Cleavage was assessed $\sim 3$ days post IVF by recording number of $1-, 2-, 4-$, and 8 - to 
16-cell embryos. Stage and/or quality scores of resultant blastocysts were recorded $\sim 8$ days post IVF as per Robertson \& Nelson (1998).

\section{Development of heat-stressed oocytes after chemical activation at 19 or 24 hIVM}

Cumulus-oocyte complexes were matured at $38.5^{\circ} \mathrm{C}$ or $41.0^{\circ} \mathrm{C}$ (heat stress was applied during first 12 hIVM). After a total of 19 or 24 hIVM, oocytes were denuded of cumulus (i.e. vortexed $\sim 4 \mathrm{~min}$ in HEPES-TALP containing $0.3 \mathrm{mg} / \mathrm{ml}$ hyaluronidase) before chemical activation with $5 \mu \mathrm{M}$ ionomycin (4 min) followed by exposure to $2 \mathrm{mM}$ 6-dimethylaminopurine $(3.5 \mathrm{~h})$ as per Susko-Parrish et al. (1994), resulting in four treatment combinations per experimental replicate. Thereafter, culture was performed in $500 \mu \mathrm{l}$ of $\mathrm{mKSOM}$ at $38.5{ }^{\circ} \mathrm{C}$ in $5.5 \% \mathrm{CO}_{2}, 7.0 \% \mathrm{O}_{2}$, and $87.5 \% \mathrm{~N}_{2}$. Ability to undergo cleavage and develop to the blastocyst stage was assessed between 71.5-74.5 and 186-194.5 h, after chemical activation respectively. Preference for chemical activation method was based on its effectiveness for supporting fetal development of embryos made via somatic cell nuclear transfer (Davies et al. 2004, Lawrence et al. 2004). This study was replicated on eight different occasions with a total of 136-280 oocytes per treatment combination.

\section{Development of heat-stressed and aged oocytes: different activation approaches and times}

Cumulus-oocyte complexes were matured at $38.5{ }^{\circ} \mathrm{C}$ or $41.0^{\circ} \mathrm{C}$ (heat stress was applied during first 12 hIVM). After a total of 24 or 30 hIVM, oocytes were chemically activated as per first study or underwent IVF resulting in eight treatment combinations per experimental replicate (Fig. 1). Ability to cleave was assessed 69-74 h after IVF or chemical activation; whereas, blastocyst development was assessed between 184 and $194 \mathrm{~h}$. This experiment was replicated on eight different occasions with a total of 164-282 cumulus-oocyte complexes cultured per treatment combination.

\section{Fertilization and pronuclear formation in control, heat- stressed, and aged oocytes}

Cumulus-oocyte complexes were matured at $38.5^{\circ} \mathrm{C}$ or $41.0^{\circ} \mathrm{C}$ (heat stress was applied during first $12 \mathrm{hIVM}$ ) for $24 \mathrm{~h}$ (control and heat stress respectively) or at $38.5^{\circ} \mathrm{C}$ for $30 \mathrm{~h}$ (aged) before undergoing IVF. At 6, 10, 13, or $16 \mathrm{~h}$ after IVF, number of oocytes that had been penetrated by sperm (i.e. underwent fertilization) was assessed. To this end, the zona pellucida was removed $(0.5 \%(\mathrm{w} / \mathrm{v})$ pronase), oocytes were fixed $(3 \%(\mathrm{w} / \mathrm{v})$ paraformaldehyde) and then stained with Hoechst $33342(0.5 \mu \mathrm{g} / \mathrm{ml})$. Stage of maternal and paternal chromatin was recorded by an individual uninformed of treatment using a Nikon Eclipse TE300 (DAPI filter: excites at 330-380 nm). In total, there were 12 treatment combinations examined per experimental replicate (i.e. three oocyte treatments assessed four different times after IVF). This experiment was performed on six different occasions with 92-180 presumptive zygotes evaluated per treatment combination. On five different occasions, subsets of control and heat-stressed oocytes were allowed to develop to the blastocyst stage to document the extent to which heat stress reduced subsequent development.

\section{Actin filaments in heat-stressed oocytes}

Cumulus-oocyte complexes were assessed at 12 and 24 hIVM after culture at $38.5^{\circ} \mathrm{C}, 41.0^{\circ} \mathrm{C}$, or $43.0{ }^{\circ} \mathrm{C}$ (heat stress applied during first $12 \mathrm{hIVM})$. Oocytes were denuded of associated cumulus cells and the zona pellucida was removed $(0.5 \%(\mathrm{w} / \mathrm{v})$ pronase). Oocytes were fixed $(3 \%(\mathrm{w} / \mathrm{v})$ paraformaldehyde), permeabilized in $0.1 \%(\mathrm{v} / \mathrm{v})$ Triton-X, and incubated in DPBS with $1 \%(\mathrm{w} / \mathrm{v}) \mathrm{BSA}(\mathrm{DPBS}+\mathrm{BSA})$ for $30 \mathrm{~min}$ to reduce nonspecific binding. Staining for F-actin was performed by incubating oocytes in $165 \mathrm{nM}$ Alexa Fluor 594 phalloidin in DPBS + BSA for $30 \mathrm{~min}$ in the dark. Stained oocytes were washed twice in DPBS + BSA before mounting on glass slides in ProLong Gold antifade solution. Negative controls were processed similarly except the Alexa Fluor 594 phalloidin was omitted. Images of different planes throughout each oocyte were captured using confocal microscopy (Leica TCS SP2, Wetzlar, Germany). Experiment was replicated on three different days of oocyte collection with a total of 157 oocytes.

\section{lonomycin-induced calcium release in control, heat- stressed, and aged oocytes}

Cumulus-oocyte complexes were matured at $38.5^{\circ} \mathrm{C}$ or $41.0^{\circ} \mathrm{C}$ (heat stress was applied during first $12 \mathrm{hIVM}$ ) for $24 \mathrm{~h}$ (control and heat stress treatments respectively) or at $38.5^{\circ} \mathrm{C}$ for 30-32 h (slightly aged). After maturation, oocytes were completely denuded of cumulus and placed in IVF-TALP (equilibrated at $38.5{ }^{\circ} \mathrm{C}$ in a humidified environment of $5.5 \%$ $\mathrm{CO}_{2}$ ) containing $2 \mu \mathrm{M}$ Fura-2/AM and pluronic acid F-127 $(0.04 \%(\mathrm{w} / \mathrm{v}))$ for minimum of $45 \mathrm{~min}$ at $38.5^{\circ} \mathrm{C}$. Thereafter, oocytes were extensively washed in HEPES-TALP (pre-warmed to $38.5^{\circ} \mathrm{C}$ ) and intracellular $\mathrm{Ca}^{2+}$ was monitored in each oocyte using a Nikon Ti-E microscope with Super Fluor $10 \times 0.5 \mathrm{NA}$ objective and heated stage adaptor (Delta T Open Dish System; Bioptechs, Butler, PA, USA). For each maturation group, pools of dye-loaded oocytes were split into two groups and washed in pre-warmed HEPES-TL (BSA-free) with or without $\mathrm{Ca}^{2+}$ before being positioned in a $40 \mu \mathrm{l}$ droplet of appropriate HEPES-TL (overlaid with mineral oil pre-warmed to $38.5^{\circ} \mathrm{C}$ ) on Delta T dish (Bioptechs) pre-coated with poly-Llysine. Individual oocyte measurements were made within 30 min of washing and placement on imaging dish. Using Nikon Elements Advanced Research Software, fluorescence values (340 and $380 \mathrm{~nm}$ excitations with $510 \mathrm{~nm}$ emission) were obtained at $1 \mathrm{~s}$ intervals; baseline levels were established (30 s) before addition of ionomycin diluted in appropriate HEPES-TL (5 $\mu \mathrm{M}$ final concentration; $300 \mathrm{~s}$ ). Intracellular $\mathrm{Ca}^{2+}$ concentrations at each time point were calculated from ratio of 340 to $380 \mathrm{~nm}$ fluorescence $(R)$ according to following formula: $\left[\mathrm{Ca}^{2+}\right]=K_{\mathrm{d}} \times \mathrm{B} \times\left(\left(\mathrm{R}-\mathrm{R}_{\min }\right) /\left(\mathrm{R}_{\max }-\mathrm{R}\right)\right)$ as described previously (Grynkiewicz et al. 1985, Fissore et al. 1992). Calibration solution of $2 \mu \mathrm{M}$ Fura-2 salt in HEPES-TL supplemented with $60 \%$ sucrose $(\mathrm{w} / \mathrm{v})$ to correct for 
intracellular viscosity (Poenie 1990) was used to determine $340-380 \mathrm{~nm}$ fluorescence ratio at zero $\left(\mathrm{R}_{\min }\right.$; containing $2 \mathrm{mM}$ EDTA) and saturating calcium ( $\mathrm{R}_{\text {max }}$; containing $2 \mathrm{mM} \mathrm{CaCl}$ ) concentrations. Ratio of fluorescence readings at $380 \mathrm{~nm}$ wavelength for zero $\mathrm{Ca}^{2+}$ to saturating $\mathrm{Ca}^{2+}$ solutions determined value of $\mathrm{B}$. Background values for subtraction were obtained by measuring calibration solution without Fura2 salt. Ratios of 0.07 and 0.48 correspond to $50 \mathrm{nM}$ and $2 \mu \mathrm{M}$ $\mathrm{Ca}^{2+}$ respectively. This experiment was replicated on three different occasions with a total of 350 oocytes.

\section{Activity of MPF and MAP kinase in control, heat- stressed, and aged oocytes}

Cumulus-oocyte complexes were matured at $38.5^{\circ} \mathrm{C}$ or $41.0^{\circ} \mathrm{C}$ (heat stress was applied during first 12 hIVM) for $24 \mathrm{~h}$ (control and heat stress respectively) or at $38.5^{\circ} \mathrm{C}$ for $30-32 \mathrm{~h}$ (slightly aged). MPF and MAP kinase activities were assessed as per Fissore et al. (1996) and Lee \& Campbell (2008) with some modifications. In brief, oocytes were denuded completely of cumulus and zona pellucidae removed before washing twice in cold $\left(4^{\circ} \mathrm{C}\right)$ DPBS containing $0.1 \%$ polyvinylpyrrolidone (DPBS-PVP). Groups of ten oocytes in $1 \mu \mathrm{l}$ of DPBS-PVP were lysed in $5 \mu \mathrm{l}$ cold kinase buffer $(45 \mathrm{mM}$ $\beta$-glycerophosphate, $12 \mathrm{mM}$ EGTA, $12 \mathrm{mM} \mathrm{MgCl} 2,0.1 \mathrm{mM}$ EDTA, $20 \mathrm{mM}$ MOPS, $0.8 \mathrm{mM}$ dithiothreitol, $20 \mu \mathrm{g} / \mathrm{ml}$ leupeptin, $20 \mu \mathrm{g} / \mathrm{ml}$ aprotinin, $10 \mu \mathrm{g} / \mathrm{ml}$ pepstatin $\mathrm{A}, 10 \mathrm{mM}$ sodium fluoride, and $1.2 \mathrm{mM}$ sodium orthovanadate) and stored at $-80{ }^{\circ} \mathrm{C}$ until further analysis. At time of assay, lysates were repeatedly thawed/frozen to facilitate complete lysis before mixing with $5 \mu \mathrm{l}$ of kinase buffer containing $2 \mathrm{mg} / \mathrm{ml}$ histone $\mathrm{H} 1$ (useful substrate for assessing MPF activity; EMD Biochemicals, Gibbstown, NJ, USA) or $1 \mathrm{mg} / \mathrm{ml}$ myelin basic protein (useful substrate for assessing MAP kinase activity; Active Motif, Carlsbad, CA, USA), 500 nM H-89 dihydrochloride hydrate (CAMP-dependent protein kinase inhibitor), $2.2 \mu \mathrm{M}$ PKA inhibitor peptide, $0.6 \mathrm{mM}$ ATP, and $250 \mu \mathrm{Ci} / \mathrm{ml}$ $\left[\gamma^{32}\right.$ P]ATP (Perkin Elmer, Waltham, MA, USA). Reactions were incubated for $30 \mathrm{~min}$ at $37^{\circ} \mathrm{C}$ and were terminated by adding $4 \times$ LDS sample buffer with dithiothreitol (Expedeon, San Diego, CA, USA). Samples were denatured $\left(70^{\circ} \mathrm{C}\right.$ for $10 \mathrm{~min}$ ) before electrophoresis on $10-20 \%$ linear gradient SDS-polyacrylamide gels (Expedeon). Dried gels were exposed to film, and autoradiographs were scanned and quantified utilizing ImageJ Software (ver 1.43u; http://imagej.nih.gov/ij/). Multiple exposures were performed to avoid saturation of exposed film to ensure proper quantification. This study was replicated on three different days with a total of three pools per treatment for MPF and 4-8 pools per treatment for MAP kinase examined for kinase activity.

\section{Statistical analysis}

In general, data were analyzed as a randomized block design, blocking on replicate, by generalized linear mixed models (PROC GLIMMIX; SAS 9.2, SAS Institute, Inc., Cary, NC, USA) with binomial or normal distributions as appropriate. When required, correction for overdispersion and/or unequal variance was implemented. Treatment differences were determined using protected least significant differences and reported as least squares means \pm s.E.M. using the inverse link option. Development of heat-stressed oocytes after chemical activation was evaluated by including the fixed effects of IVM temperature $\left(38.5^{\circ} \mathrm{C}\right.$ or $\left.41.0^{\circ} \mathrm{C}\right)$ and activation time (19 and 24 hIVM) in the statistical model. To examine development of heat-stressed oocytes after chemical activation or IVF at 24 or 30 hIVM, main effects included IVM temperature $\left(38.5^{\circ} \mathrm{C}\right.$ or $41.0^{\circ} \mathrm{C}$ ), activation time (24 or 30 hIVM), activation method, and all interactions. Fertilization and pronuclear formation in control, heat-stressed, and aged oocytes were evaluated by including main effects of treatment (control, heat stress, or aged), evaluation time (6, 10, 13, and $16 \mathrm{~h}$ after (VF), and the interaction. Activity of MPF and MAP kinase was evaluated by including the main effect of treatment (control, heat stress, and aged) in statistical model.

Differences in control, heat-stressed, and aged oocytes response to ionomycin were determined by examining various parameters of the induced intracellular increase in calcium. Initiation and termination of $\left[\mathrm{Ca}^{2+}\right]_{i}$ release was determined by fitting a four straight line segmented nonlinear model (PROC NLIN, SAS 9.2), with segments consisting of an initial flat baseline, then a rise to the peak, followed by a fall to the termination of release, and then a final plateau which generally was not flat. Join points provided estimates for initiation and termination, except in a few cases of unusual response where estimates were manually adjusted by a few seconds to better match visually obvious breaks in the $\left[\mathrm{Ca}^{2+}\right]_{i}$ pattern. Once initiation and termination times were estimated, variables of interest were calculated from the data. Variables included initial basal level (average intracellular concentration before ionomycin addition), time of rise (duration from initiation of release until maximum concentration was observed), amplitude of response (difference between initial basal and maximum concentration), time of decline (duration from time of maximal concentration until termination of release), response duration (total time from initiation to termination of $\left[\mathrm{Ca}^{2+}\right]_{i}$ release), area under the curve (representation of total change in intracellular calcium), and post-release plateau (average intracellular concentration post termination of release until end of experiment). Resulting data were tested for normality (Shapiro-Wilk $W \geq 0.90$ ) and subjected to logarithmic transformation before analysis with main effect of maturation condition (control, heat stress, or aged) and blocking on replicate by mixed model procedure of SAS. Values were back transformed to original scale for reporting.

\section{Declaration of interest}

The authors declare that there is no conflict of interest that could be perceived as prejudicing the impartiality of the research reported.

\section{Funding}

This research was supported in part by USDA Hatch Funds, the State of Tennessee through UT AgResearch, and the Department of Animal Science. 


\section{Acknowledgements}

Appreciation is extended to T J Wilson, Nancy Rohrbach, Jessy Harris, Matt Backus, and Russell Harris for technical assistance associated with conducting experiments. We also thank Dr J Shawn Goodwin (Meharry Medical College Nashville TN), Cumberland Dugan (Nikon) and Dr Rafael A Fissore (University of Massachusetts Amherst) whose invaluable assistance or advice were essential to completion of the calcium measurement experiment.

\section{References}

Agung B, Otoi T, Wongsrikeao P, Taniguchi M, Shimizu R, Watari H \& Nagai T 2006 Effect of maturation culture period of oocytes on the sex ratio of in vitro fertilized bovine embryos. Journal of Reproduction and Development 52 123-127. (doi:10.1262/jrd.17055)

Ajduk A, Malagocki A \& Maleszewski M 2008 Cytoplasmic maturation of mammalian oocytes: development of a mechanism responsible for sperm-induced $\mathrm{Ca}^{2+}$ oscillations. Reproductive Biology 8 3-22.

Andreu-Vazquez C, Lopez-Gatius F, Garcia-Ispierto I, Maya-Soriano MJ, Hunter RH \& Lopez-Bejar M 2010 Does heat stress provoke the loss of a continuous layer of cortical granules beneath the plasma membrane during oocyte maturation? Zygote 18 293-299. (doi:10.1017/ S0967199410000043)

Baumgartner AP \& Chrisman CL 1981 Ovum morphology after hyperthermic stress during meiotic maturation and ovulation in the mouse. Journal of Reproduction and Fertility 61 91-96. (doi:10.1530/jrf. $0.0610091)$

Berridge MJ, Bootman MD \& Roderick HL 2003 Calcium signalling: dynamics, homeostasis and remodelling. Nature Reviews. Molecular Cell Biology 4 517-529. (doi:10.1038/nrm1155)

Biggers JD, McGinnis LK \& Raffin M 2000 Amino acids and preimplantation development of the mouse in protein-free potassium simplex optimized medium. Biology of Reproduction 63 281-293. (doi:10.1095/ biolreprod63.1.281)

de Castro e Paula LA \& Hansen PJ 2007 Interactions between oxygen tension and glucose concentration that modulate actions of heat shock on bovine oocytes during in vitro maturation. Theriogenology 68 763-770. (doi:10.1016/j.theriogenology.2007.06.005)

Davies CJ, Hill JR, Edwards JL, Schrick FN, Fisher PJ, Eldridge JA \& Schlafer DH 2004 Major histocompatibility antigen expression on the bovine placenta: its relationship to abnormal pregnancies and retained placenta. Animal Reproduction Science 82-83 267-280. (doi:10.1016/ j.anireprosci.2004.05.016)

Dedkova EN, Sigova AA \& Zinchenko VP 2000 Mechanism of action of calcium ionophores on intact cells: ionophore-resistant cells. Membrane and Cell Biology 13 357-368.

Dutt RH 1963 Critical period for early embryo mortality in ewes exposed to high ambient temperature. Journal of Animal Science 22 713-719.

Edwards JL \& Hansen PJ 1996 Elevated temperature increases heat shock protein 70 synthesis in bovine two-cell embryos and compromises function of maturing oocytes. Biology of Reproduction 55 341-346. (doi:10.1095/biolreprod55.2.341)

Edwards JL \& Hansen PJ 1997 Differential responses of bovine oocytes and preimplantation embryos to heat shock. Molecular Reproduction and Development 46 138-145. (doi:10.1002/(SICI)1098-2795(199702)46: $2<138:: A I D-M R D 4>3.0 .(O ; 2-R)$

Edwards JL, Saxton AM, Lawrence JL, Payton RR \& Dunlap JR 2005 Exposure to a physiologically relevant elevated temperature hastens in vitro maturation in bovine oocytes. Journal of Dairy Science $\mathbf{8 8}$ 4326-4333. (doi:10.3168/jds.S0022-0302(05)73119-2)

Edwards JL, Bogart AN, Rispoli LA, Saxton AM \& Schrick FN 2009 Developmental competence of bovine embryos from heat-stressed ova. Journal of Dairy Science 92 563-570. (doi:10.3168/jds.2008-1495)

Eichenlaub-Ritter U, Chandley AC \& Gosden RG 1986 Alterations to the microtubular cytoskeleton and increased disorder of chromosome alignment in spontaneously ovulated mouse oocytes aged in vivo: an immunofluorescence study. Chromosoma 94 337-345. (doi:10.1007/ BF00328633)

Eliyahu E, Tsaadon A, Shtraizent N \& Shalgi R 2005 The involvement of protein kinase $\mathrm{C}$ and actin filaments in cortical granule exocytosis in the rat. Reproduction 129 161-170. (doi:10.1530/rep.1.00424)

Fissore RA, Dobrinsky JR, Balise JJ, Duby RT \& Robl JM 1992 Patterns of intracellular $\mathrm{Ca}^{2+}$ concentrations in fertilized bovine eggs. Biology of Reproduction 47 960-969. (doi:10.1095/biolreprod47.6.960)

Fissore RA, He CL \& Vande Woude GF 1996 Potential role of mitogenactivated protein kinase during meiosis resumption in bovine oocytes. Biology of Reproduction 55 1261-1270. (doi:10.1095/biolreprod55.6. 1261)

Funahashi H, Stumpf TT, Cantley TC, Kim NH \& Day BN 1995 Pronuclear formation and intracellular glutathione content of in vitro-matured porcine oocytes following in vitro fertilisation and/or electrical activation. Zygote 3 273-281. (doi:10.1017/S0967199400002677)

Grynkiewicz G, Poenie M \& Tsien RY 1985 A new generation of $\mathrm{Ca}^{2+}$ indicators with greatly improved fluorescence properties. Journal of Biological Chemistry $2603440-3450$.

He CL, Damiani P, Parys JB \& Fissore RA 1997 Calcium, calcium release receptors, and meiotic resumption in bovine oocytes. Biology of Reproduction 57 1245-1255. (doi:10.1095/biolreprod57.5.1245)

Igarashi H, Takahashi E, Hiroi M \& Doi K 1997 Aging-related changes in calcium oscillations in fertilized mouse oocytes. Molecular Reproduction and Development 48 383-390. (doi:10.1002/(SICl)1098-2795 (199711)48:3 <383::AID-MRD12>3.0.CO;2-X)

Ju JC \& Tseng JK 2004 Nuclear and cytoskeletal alterations of in vitro matured porcine oocytes under hyperthermia. Molecular Reproduction and Development 68 125-133. (doi:10.1002/mrd.20054)

Kim M, Geum D, Khang I, Park YM, Kang BM, Lee KA \& Kim K 2002 Expression pattern of HSP25 in mouse preimplantation embryo: heat shock responses during oocyte maturation. Molecular Reproduction and Development 61 3-13. (doi:10.1002/mrd.1125)

Kruip TAM, Cran DG, van Beneden TH \& Dieleman SJ 1983 Structural changes in bovine oocytes during final maturation in vivo. Gamete Research 8 29-47. (doi:10.1002/mrd.1120080105)

Lawrence JL, Payton RR, Godkin JD, Saxton AM, Schrick FN \& Edwards JL 2004 Retinol improves development of bovine oocytes compromised by heat stress during maturation. Journal of Dairy Science 87 2449-2454. (doi:10.3168/jds.S0022-0302(04)73368-8)

Lee JH \& Campbell KH 2006 Effects of enucleation and caffeine on maturation-promoting factor (MPF) and mitogen-activated protein kinase (MAPK) activities in ovine oocytes used as recipient cytoplasts for nuclear transfer. Biology of Reproduction 74 691-698. (doi:10.1095/biolreprod. 105.043885)

Lee JH \& Campbell KH 2008 Caffeine treatment prevents age-related changes in ovine oocytes and increases cell numbers in blastocysts produced by somatic cell nuclear transfer. Cloning Stem Cells $\mathbf{1 0}$ 381-390. (doi:10.1089/clo.2007.0091)

Li GP, Liu Y, Bunch TD, White KL \& Aston KI 2005 Asymmetric division of spindle microtubules and microfilaments during bovine meiosis from metaphase I to metaphase III. Molecular Reproduction and Development 71 220-226. (doi:10.1002/mrd.20255)

Ma W, Zhang D, Hou Y, Li YH, Sun QY, Sun XF \& Wang WH 2005 Reduced expression of MAD2, BCL2, and MAP kinase activity in pig oocytes after in vitro aging are associated with defects in sister chromatid segregation during meiosis II and embryo fragmentation after activation. Biology of Reproduction 72 373-383. (doi:10.1095/biolreprod.104.030999)

Matsuzuka T, Ozawa M, Hirabayashi M, Ushitani A \& Kanai Y 2004 Developmental competence and glutathione content of maternally heat-stressed mouse oocytes and zygotes. Animal Science Journal 75 117-124. (doi:10.1111/j.1740-0929.2004.00165.x)

Meng XQ, Zheng KG, Yang Y, Jiang MX, Zhang YL, Sun QY \& Li YL 2006 Proline-rich tyrosine kinase2 is involved in F-actin organization during in vitro maturation of rat oocyte. Reproduction 132 859-867. (doi:10. 1530/rep.1.01212)

Morgan AJ \& Jacob R 1994 lonomycin enhances $\mathrm{Ca}^{2+}$ influx by stimulating store-regulated cation entry and not by a direct action at the plasma membrane. Biochemical Journal 300 665-672.

Nabenishi H, Ohta H, Nishimoto T, Morita T, Ashizawa K \& Tsuzuki Y 2011 The effects of cysteine addition during in vitro maturation on the 
developmental competence, ROS, GSH and apoptosis level of bovine oocytes exposed to heat stress. Zygote [in press]. (doi:10.1017/ S0967199411000220)

Ozil JP 1990 The parthenogenetic development of rabbit oocytes after repetitive pulsatile electrical stimulation. Development 109 117-127.

Ozil JP \& Huneau D 2001 Activation of rabbit oocytes: the impact of the $\mathrm{Ca}^{2+}$ signal regime on development. Development 128 917-928.

Ozil JP, Banrezes B, Toth S, Pan H \& Schultz RM $2006 \mathrm{Ca}^{2+}$ oscillatory pattern in fertilized mouse eggs affects gene expression and development to term. Developmental Biology 300 534-544. (doi:10.1016/j.ydbio.2006.08.041)

Parrish JJ, Susko-Parrish J, Winer MA \& First NL 1988 Capacitation of bovine sperm by heparin. Biology of Reproduction 38 1171-1180. (doi:10.1095/biolreprod38.5.1171)

Payton RR, Romar R, Coy P, Saxton AM, Lawrence JL \& Edwards JL 2004 Susceptibility of bovine germinal vesicle-stage oocytes from antral follicles to direct effects of heat stress in vitro. Biology of Reproduction 71 1303-1308. (doi:10.1095/biolreprod.104.029892)

Poenie M 1990 Alteration of intracellular Fura-2 fluorescence by viscosity: a simple correction. Cell Calcium 11 85-91. (doi:10.1016/0143-4160 (90)90062-Y)

Putney DJ, Mullins S, Thatcher WW, Drost M \& Gross TS 1989 Embryonic development in superovulated dairy cattle exposed to elevated ambient temperatures between the onset of estrus and insemination. Animal Reproduction Science 19 37-51. (doi:10.1016/0378-4320(89)90045-6)

Robertson I \& Nelson RE 1998 Certification and identification of the embryo. In Manual of the International Embryo Transfer Society, 3 edn, pp 103-107. Eds DA Stringfellow \& SM Seidel. Savoy, IL: International Embryo Transfer Society.

Roth Z \& Hansen PJ 2004a Involvement of apoptosis in disruption of developmental competence of bovine oocytes by heat shock during maturation. Biology of Reproduction 71 1898-1906. (doi:10.1095/ biolreprod.104.031690)

Roth Z \& Hansen PJ 2004b Sphingosine 1-phosphate protects bovine oocytes from heat shock during maturation. Biology of Reproduction 71 2072-2078. (doi:10.1095/biolreprod.104.031989)

Roth Z \& Hansen PJ 2005 Disruption of nuclear maturation and rearrangement of cytoskeletal elements in bovine oocytes exposed to heat shock during maturation. Reproduction 129 235-244. (doi:10. 1530/rep.1.00394)

Rutigliano HM, Lima FS, Cerri RL, Greco LF, Vilela JM, Magalhaes V, Silvestre FT, Thatcher WW \& Santos JE 2008 Effects of method of presynchronization and source of selenium on uterine health and reproduction in dairy cows. Journal of Dairy Science 91 3323-3336. (doi:10.3168/jds.2008-1005)

Schrock GE, Saxton AM, Schrick FN \& Edwards JL 2007 Early in vitro fertilization improves development of bovine ova heat stressed during in vitro maturation. Journal of Dairy Science 90 4297-4303. (doi:10. 3168/jds.2007-0002)

Soto P \& Smith LC 2008 BH4 peptide derived from Bcl-xL and Bax-inhibitor peptide suppresses apoptotic mitochondrial changes in heat stressed bovine oocytes. Molecular Reproduction and Development 76 637-646. (doi:10.1002/mrd.20986)

Stott GH \& Williams RJ 1962 Causes of low breeding efficiency in dairy cattle associated with seasonal high temperatures. Journal of Dairy Science 45 1369-1375. (doi:10.3168/jds.S0022-0302(62)89628-3)

Sugiyama S, McGowan M, Phillips N, Kafi M \& Young M 2007 Effects of increased ambient temperature during IVM and/or IVF on the in vitro development of bovine zygotes. Reproduction in Domestic Animals 42 271-274. (doi:10.1111/j.1439-0531.2006.00776.x)

Susko-Parrish JL, Leibfried-Rutledge ML, Northey DL, Schutzkus V \& First NL 1994 Inhibition of protein kinases after an induced calcium transient causes transition of bovine oocytes to embryonic cycles without meiotic completion. Developmental Biology 166 729-739. (doi:10. 1006/dbio.1994.1351)

Suzuki H, Liu L \& Yang X 1999 Age-dependent development and surface ultrastructural changes following electrical activation of bovine oocytes. Reproduction, Fertility, and Development 11 159-165. (doi:10.1071/ RD98091)

Takahashi T, Saito H, Hiroi M, Doi K \& Takahashi E 2000 Effects of aging on inositol 1,4,5-triphosphate-induced $\mathrm{Ca}^{2+}$ release in unfertilized mouse oocytes. Molecular Reproduction and Development 55 299-306. (doi:10.1002/(SICI)1098-2795(200003)55:3<299::AID-MRD8>3.0. $\mathrm{CO} ; 2-\mathrm{G})$

Tarin JJ 1996 Potential effects of age-associated oxidative stress on mammalian oocytes/embryos. Molecular Human Reproduction 2 717-724. (doi:10.1093/molehr/2.10.717)

Tatone C, Carbone MC, Gallo R, Delle Monache S, Di Cola M, Alesse E \& Amicarelli F 2006 Age-associated changes in mouse oocytes during postovulatory in vitro culture: possible role for meiotic kinases and survival factor BCL2. Biology of Reproduction 74 395-402. (doi:10. 1095/biolreprod.105.046169)

Tian XC, Lonergan P, Jeong BS, Evans AC \& Yang X 2002 Association of MPF, MAPK, and nuclear progression dynamics during activation of young and aged bovine oocytes. Molecular Reproduction and Development 62 132-138. (doi:10.1002/mrd.10072)

Tompkins EC, Heidenreich CJ \& Stob M 1967 Effect of post-breeding thermal stress on embyronic mortality in swine. Journal of Animal Science 26 377-380.

Tseng JK \& Ju JC 2009 Calcium release of heat-shocked porcine oocytes induced by thimerosal or inositol 1,4,5-trisphosphate $\left(\mathrm{IP}_{3}\right)$. Animal Reproduction Science 111 41-53. (doi:10.1016/j.anireprosci. 2008.02.007)

Tseng JK, Tang PC \& Ju JC 2006 In vitro thermal stress induces apoptosis and reduces development of porcine parthenotes. Theriogenology $\mathbf{6 6}$ 1073-1082. (doi:10.1016/j.theriogenology.2006.03.003)

Tseng JK, Liu HK, Lin TA, Yang CR, Yang X \& Ju JC 2009 Calcium release and development of heat-shocked porcine oocytes after nucleusooplasm reconstruction. Cloning Stem Cells 11 557-563. (doi:10.1089/ clo.2009.0025)

Vincent C, Cheek TR \& Johnson MH 1992 Cell cycle progression of parthenogenetically activated mouse oocytes to interphase is dependent on the level of internal calcium. Journal of Cell Science 103 389-396.

Wang WH, Abeydeera LR, Prather RS \& Day BN 2000 Polymerization of nonfilamentous actin into microfilaments is an important process for porcine oocyte maturation and early embryo development. Biology of Reproduction 62 1177-1183. (doi:10.1095/biolreprod62.5.1177)

Wang L, White KL, Reed WA \& Campbell KD 2005 Dynamic changes to the inositol 1,4,5-trisphosphate and ryanodine receptors during maturation of bovine oocytes. Cloning Stem Cells 7 306-320. (doi:10. 1089/clo.2005.7.306)

Wang JZ, Sui HS, Miao DQ, Liu N, Zhou P, Ge L \& Tan JH 2009 Effects of heat stress during in vitro maturation on cytoplasmic versus nuclear components of mouse oocytes. Reproduction 137 181-189. (doi:10. 1530/REP-08-0339)

Ward F, Enright B, Rizos D, Boland M \& Lonergan P 2002 Optimization of in vitro bovine embryo production: effect of duration of maturation, length of gamete co-incubation, sperm concentration and sire. Theriogenology 57 2105-2117. (doi:10.1016/S0093-691X(02) 00696-9)

Xu Z, Abbott A, Kopf GS, Schultz RM \& Ducibella T 1997 Spontaneous activation of ovulated mouse eggs: time-dependent effects on M-phase exit, cortical granule exocytosis, maternal messenger ribonucleic acid recruitment, and inositol 1,4,5-trisphosphate sensitivity. Biology of Reproduction 57 743-750. (doi:10.1095/biolreprod57.4.743)

Yoshida S \& Plant S 1992 Mechanism of release of $\mathrm{Ca}^{2+}$ from intracellular stores in response to ionomycin in oocytes of the frog Xenopus laevis. Journal of Physiology 458 307-318.

Zhandi M, Towhidi A, Nasr-Esfahani MH, Eftekhari-Yazdi P \& Zare-Shahneh A 2009 Unexpected detrimental effect of insulin like growth factor-1 on bovine oocyte developmental competence under heat stress. Journal of Assisted Reproduction and Genetics 26 605-611. (doi:10.1007/s10815009-9364-0)

Received 4 February 2011

First decision 28 February 2011

Revised manuscript received 28 September 2011

Accepted 12 October 2011 